\title{
Improving students' HOTS through the disconnection stages of learning synthesis organic compounds
}

\author{
Liliasari* \\ Pendidikan Kimia \\ Universitas Cendrawasih \\ Jayapura, Indonesia \\ liliasari@upi.edu
}

\author{
LusiaNarsia Amsad, Asep kadarohman, Ratnaningsih E. Sardjono \\ Pendidikan Kimia \\ Universitas Pendidikan Indonesia \\ Bandung, Indonesia
}

\begin{abstract}
Learning synthetic organic chemistry has several stages of the learning material that should be followed by students. One of the importance stages in learning organic synthesis is the disconnection stages. This study aims to be able to find out the improvement of students'HOTS through learning stages of organic synthesis. Respondents from this study were 16 students from one state university in Papua. This research is a quasi experimental by one group pre test and post test design. The essay test used as the instrument that to be able to find out students' HOTS. The data obtain were pre test and post test data, therefore it can be seen the value of $\mathrm{N}$-gain. Nonparametric statistics were used in this study.There were 4 indicators of HOTS used in this study. The results showed that the highest $\mathrm{N}$-gain was 0.719 and it found in indicator elementary clarification for sub indicator analyze arguments. The lowest $\mathrm{N}$-gain value found in indicator basic support in sub indicator judging the credibility of source. According to the $\mathbf{N}$-gain value for indicator elementary clarification for sub indicator analyze arguments is the high category while the other indicators are in the medium category. From this research we recognize that there is a significant influence on HOTS' students and the implementation of disconnection stages in learning the synthesis of organic compounds.
\end{abstract}

Keywords: Improvement, students' HOTS, disconnetion stages, organic synthesis

\section{INTRODUCTION}

High Order Thinking Skill (HOTS) are indispensable for students in learning the synthesis of organic compounds. HOTS can make a philosophical shift for judging students' ability. Because it is not just only emphasizing output but rather looking at the process. In another view that students change from just learning towards to meaningful learning. HOTS is the most important skill in learning while use problem solving, investigation, and discovery as a method. It is the systematic approach to evaluate information wisely for find the most feasible solution for various structured and unstructured problems [2]. HOTS can make students connected the new concepts to previous learning with correctly understanding [3]. Research found that HOTS can be developed in learning $[4,5]$.

Learning synthetic organic chemistry is a very complex learning [6]. Students need to integrate their understanding of basic concepts to solve an organic chemical synthesis problem [7]. Learning synthetic organic chemistry also has material stages that need to be mastered by students. Thus the learning of synthetic organic chemistry requires the presence of students' HOTS to complete the stages of the learning material. Students need to think about pathways to design the stages through various aspects of the concept [8].

The disconnection stage is one of the stages that require students' HOTS to be able to integrate various aspects needed in this stage. In this case there are several aspects of the disconnection stage which are the focus of this research, including: stability of carbocation, reagent, starting material, reaction type, reaction conditions, and analyze the stereoselectivity and regioselectivity of compounds based on target molecules [7].

The research purposes to increase HOTS students through learning stages of synthetic organic chemistry. In this study only certain stages of organic chemistry learning were used. Furthermore, it will be seen also how much influence from the implementation of learning stages of organic chemical synthesis to the increase of HOTS students.

\section{METHOD}

In this study descriptive method was used from the results of student essay tests. The research subjects were 16 students from one state university in Papua. They are students in the fourth year. The student has attended lectures on organic chemistry 1,2 and advanced organic chemistry.

The data obtained came from the students' answers to essay tests on the aspect of disconnection stage to synthesize the target molecules compounds.

After that the results of the student's answers were analyzed. To find out HOTS'students at the disconnection stage, then focus on HOTS students on the indicators: (1) Elementary clarification in sub indicators on analyze arguments; (2) Basic support in sub indicator judging the credibility of source; (3) Inference on sub indicator deducing and judging deduction; and (4) Advanced Clarification in sub indicator identifying assumptions. HOTS indicators and sub-indicators used refer to the indicators of Ennis's critical thinking skills [10].

The instrument used to measure HOTS is essay test. Essay tests provided include disconnection stages that are focused on certain aspects. Some examples of essay tests 
given related to the retro-synthetic stages of organic compounds can be seen in Figure 1.

In this study using $\mathrm{N}$-gain calculations to determine whether or not there is an increase in students' HOTS. The criteria for $\mathrm{N}$-gain are: (1) if $\mathrm{g} \geq 0.7$, the resulting $\mathrm{N}$-gain is in the high category; (2) if $0.7>\mathrm{g} \geq 0.3$, then the resulting $\mathrm{N}$-gain is in the medium category, and (3) if $\mathrm{g}<0.3$, the resulting $\mathrm{N}$-gain is in the low category [10]. The statistics used were nonparametric statistics, namely the Wilcoxon test with a critical point of 0.05 using this study because we want to know the difference between the pre-test and posttest results [11].

\section{RESULTS OF RESEARCH AND DISCUSSION}

Learning in organic synthesis requires a variety of integration of basic concepts that are already owned by students. Students need to have HOTS in completing the stages of learning organic synthesis. Learning in organic synthesis also consists of various stages in learning, one of which is the disconnection stage.

In this study, the disconnection stage is divided into HOTS indicators. Then HOTS students were reviewed at each disconnection stage before and after learning which emphasized the disconnection stage of organic compounds. In this case the results of the student essay test can be seen in Table I.

Based on the data in Table 1, it can be seen that the acquisition of $\mathrm{N}$-gain value for the whole HOTS indicators are in the range of high and medium category. For code a, which provides indicator elementary clarification and sub indicators analyzing arguments has the highest $\mathrm{N}$-gain value of 0.800 . The $\mathrm{N}$-gain value of code a fullfil the criteria for high category. Meanwhile we found the lowest $\mathrm{N}$-gain value is in indicator of basic support in sub indicator judging the credibility of source. The $\mathrm{N}$-gain value is 0.549 in the medium category. In addition, the others HOTS indicators

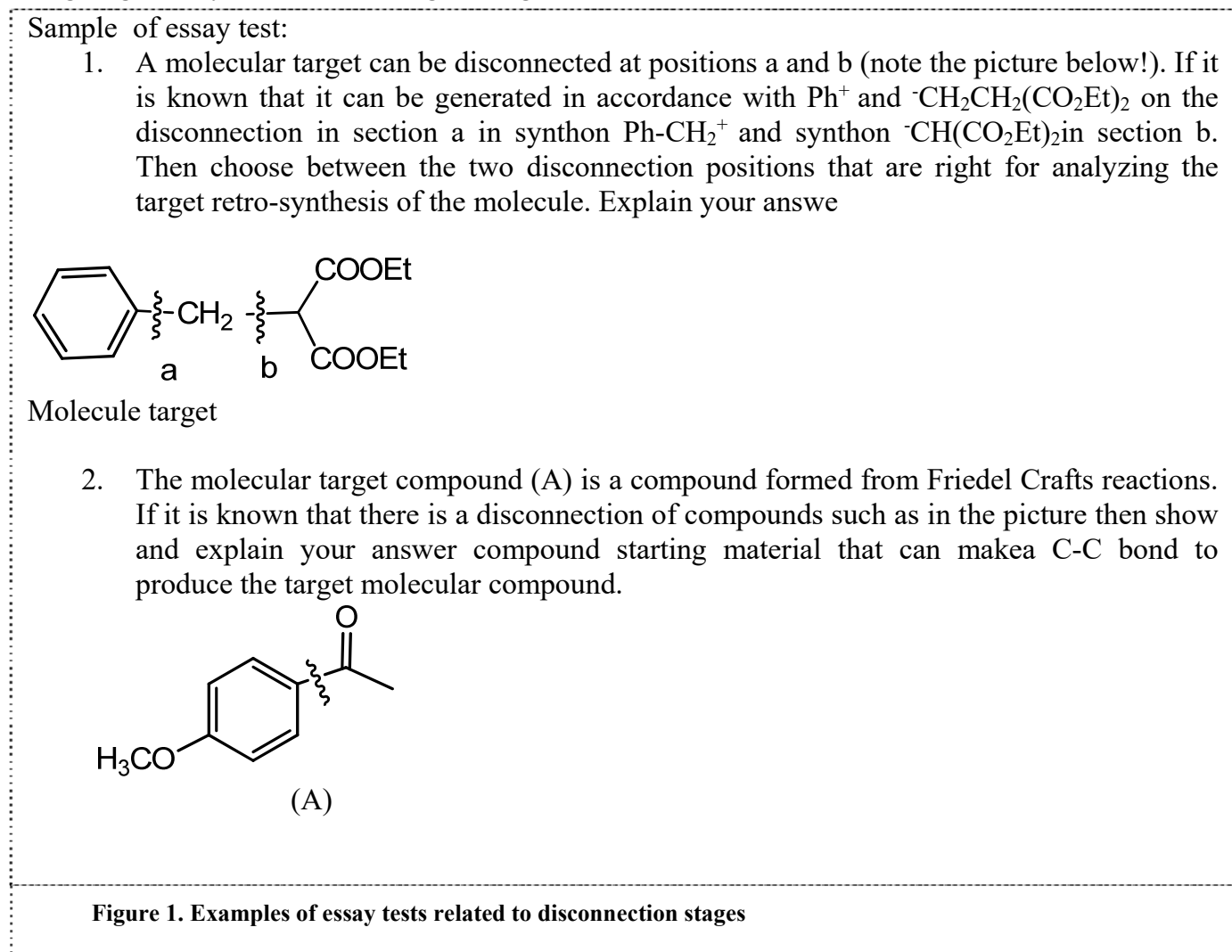

TABLE I. RESULT OF STUDENTS' HOTS AT THE DISCONNECTION STAGE

\begin{tabular}{|c|l|c|c|c|}
\hline Code & \multicolumn{1}{|c|}{ Indicator } & $\begin{array}{c}\text { Number of } \\
\text { questions }\end{array}$ & N-Gain & Category \\
\hline $\mathrm{a}$ & $\begin{array}{l}\text { Elementary clarification in sub } \\
\text { indicators on analyze arguments }\end{array}$ & 1,2 & 0.719 & high \\
\hline $\mathrm{b}$ & $\begin{array}{l}\text { Basic support in sub indicator } \\
\text { judging the credibility of source }\end{array}$ & $7,8,9$ & 0.549 & medium \\
\hline $\mathrm{c}$ & $\begin{array}{l}\text { Inference on sub indicator } \\
\text { deducing and judging deduction }\end{array}$ & $\begin{array}{c}3,5,6,10, \\
11,12\end{array}$ & 0.596 & medium \\
\hline $\mathrm{d}$ & $\begin{array}{l}\text { Advance Clarification in sub } \\
\text { indicator identifying assumptions }\end{array}$ & 4 & 0.690 & medium \\
\hline
\end{tabular}


which is advance clarification in sub indicator identifying assumptions and indicator Interference in the sub indicator deduction and judging the deduction have $\mathrm{N}$-gain value are 0.690 and 0.596 But we can also see the N-gain spread from the HOTS indicator on each question on the $\mathrm{N}$-gain diagram as shown in Figure 2.

Based on Figure 2, almost all indicators from the disconnection stage are in the medium criteria. Overall, the increase in all aspects is in the medium category. But it is different in the code a that consists question number 1 and 2 which indicate a high increase. This is possible because this indicator are the basic level in HOTS. In the fact, for questions 1 and 2 refers an elementary clarification. Students are familiar with the form of questions given. This resulted in getting the material related to the problem, so students became more developed in answering the questions given by HOTS. This is in accordance with the results of research which suggests that there needs to be a good conceptual understanding and strategy of students in solving the problems of synthesis of organic compounds $[12,13]$.

The results of learning organic synthesis using disconnection stages can also be displayed the results of the pre test and post test which can be seen in Figure 3.
Based on the diagram in Figure 3 it is known that the smallest student pre test and post test results in indicator $\mathrm{d}$. The indicator is advance clarification in sub indicator identifying assumptions which is a high level in HOTS. The $\mathrm{d}$ indicator just consists one question (questions 4), which are related to the analysis of stereoselectivity, regioselectivity, and retrosynthesis of target molecular compounds. We can also said that because of the lack of understanding about basic concepts of stereoselectivity and regioselectivity possessed by students. On the contrary, from Figure 3, it can also be seen that the biggest pre test results based on indicators is indicator $\mathrm{c}$. The indicator $\mathrm{c}$ is inference on sub indicator deducing and judging deduction. This indicator consists questions number $3,5,6,10,11$, and 12. If we take problem number 5 as the example for this indicators. We found that the question was about analysing Friedel Crafts reagents from the corresponding target molecular compounds.

As noted above, the results of the high HOTS students in the number 5 pre test are related to the concepts of Friedel

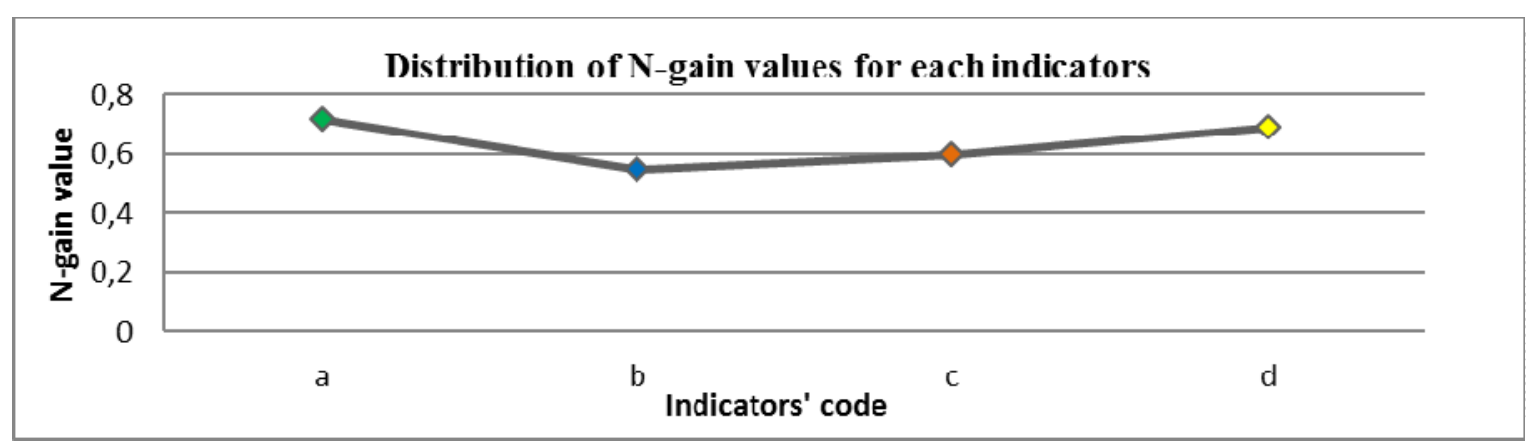

Figure 2. Distribution of N-gain values for each indicator

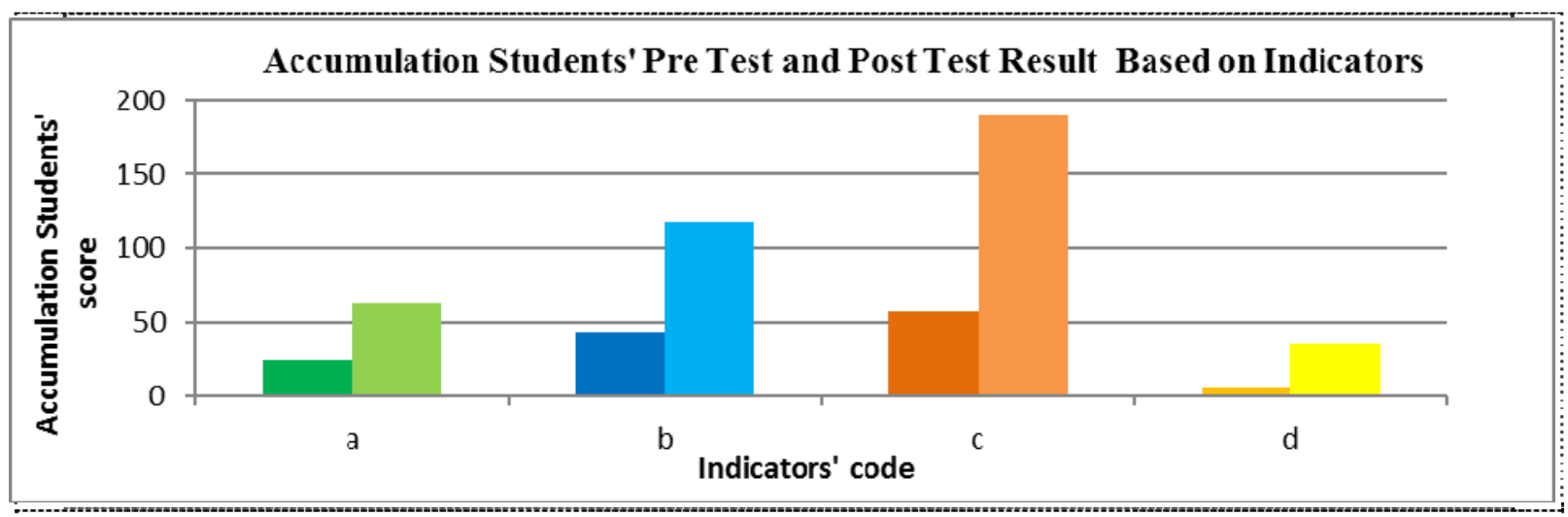

Figure 3. Diagram of Students' Pre Test and Post Test Result Based on Indicators 
crafts reagents that have been mastered by students. This makes it difficult for students to be able to answer the question.

The biggest post test results are still found in indicator $\mathrm{c}$. If we investigate one question in this indicators we found as the example in question number 9. This question is related to the problem of determining reagents, reaction conditions, type of reaction, starting material and the corresponding target molecular compounds. For students, questions like this are only repetitions for them so they can answer well in this matter in the post test. The HOTS indicator of students in problem number 5 is to give a simple explanation on the sub indicators considering credibility while at number 9 is to refer to the sub-indicator deduaction and judging the deduction. The acquisition of the post test results is different from the results of the pre-test, the acquisition of which is much smaller. It can be seen that students can improve their HOTS by integrating the concept of reagents, starting materials, conditions and types of reactions well. In previous studies it was known that students need to be given the problem of organic synthesis by using mechanistic solutions. Through this task, students understand more about how to solve organic chemical problems mechanically [15].

In addition, based on nonparametric statistics, we use the Wilcoxon test to see whether there is an influence or not of learning by using the student's pre-test and post-test scores, then we get it as in table 2 .

TABLE II. RESULT TEST OF WILCOXON

\begin{tabular}{|l|c|}
\hline & post tes - pre tes \\
\hline$Z$ & $-3.061^{\mathrm{b}}$ \\
\hline Asymp. Sig. (2-tailed) & .002 \\
\hline
\end{tabular}

a. Wilcoxon Signed Ranks Test

b. b. Based on negative ranks

Based on Asymp value table 2. Sig. (2-tailed) is 0.002, which means smaller than 0.05 indicates a significant influence from the results of the pre-test and post-test. This applies to a significant level of $5 \%$. The Wilcoxon test results show that learning of organic synthesis through disconnection stages can increase student HOTS.

In order to be higher at the HOTS level of students, it is necessary to encourage students to change their study habits from memorization to meaningful learning and this needs to be done to achieve a higher level of learning outcomes [14]. Students make a study based on authentic and real problems that are similar to the complex problems faced by scientists which have an impact on HOTS students and study independently, and gain a deeper learning experience. This is a process of assimilation that must be passed by students to be able to turn into practitioners or scientists in the field of organic chemistry [15].

\section{CONCLUSION}

Based on the results of data analysis it can be concluded that the lowest $\mathrm{N}$-gain value found in indicator basic support in sub indicator judging the credibility of source. According to the $\mathrm{N}$-gain value for indicator elementary clarification for sub indicator analyze arguments is the high category while the other indicators are in the medium category. It is also known that there is a significant influence on HOTS students on the implementation of disconnection stages in the learning of the synthesis of organic compounds. This shows the learning of organic chemical synthesis through the disconnection stage can increase the HOTS of students. However, there is a need for learning that makes students learn independently and gain a more in-depth learning experience, so that it can further enhance student HOTS.

\section{ACKNOWLEDGEMENT}

V.We wish to thank all the team of organic lecturers and laboratory assisted at one of the state universities in Papua who have helped in data collection

\section{REFERENCES}

[1] Thompson C., "Critical Thinking across the Curriculum : Process over Output 1" 1-7., 2011.

[2] Laxman K., "Computers \& Education A conceptual framework mapping the application of information search strategies to well and ill-structured problem solving," Comput. Educ, 2010,55 pp. 513-26.

[3] Hakim A., Kadarohman A. and Syah Y. M., "Improvement of Student Critical Thinking Skills with the Natural Product Mini Project Laboratory Learning,", 2016, 16 pp. 322-8.

[4] An I 2014 Dwyer, C., M. Hogan and I. Stewart, "An integrated critical thinking framework for the $21 \mathrm{st}$ century," 2014, pp. 43-52.

[5] Cowden C. D. and Santiago M. F., "Interdisciplinary Explorations: Promoting Critical Thinking via Problem-Based Learning in an Advanced Biochemistry Class".

[6] Strickland A. M., Kraft A. and Bhattacharyya G., "What happens when representations fail to represent? Graduate students' mental models of organic chemistry diagrams," Chem. Educ. Res. Pr, 2010, 11 293-301.

[7] Amsad L N, Liliasari and Kadarohman A., "Integrating Students' Understanding of Prerequisite Concepts into Capability to Synthesize Organic Compounds," J. Phys. Conf. Ser, 2017, 895.

[8] Flynn A. B., "Developing Problem-Solving Skills through Retrosynthetic Analysis and Clickers in Organic Chemistry,", 2011, pp. 1496-500.

[9] Ennis R. H. A., "Logical Basis for Measuring Critical Thinking Skills".

[10] Hake, R, R., "Analyzing Change/Gain Scores.AREA-D American Education Research Association's Devision," D, Measurement and Reasearch Methodology. 
[11] Journal S, Statistical A. and Dec N., "Use of Ranks in One-Criterion Variance Analysis" Author (s): William $H$. Kruskal and W. Allen Wallis Published by: American Statistical Association Stable URL: http://www.jstor.org/stable/2280779, 2009, 47 583621.

[12] Carlisle D. and Nieswandt M., "Research and Practice Fostering spatial skill acquisition," general Chem. Educ. Res. Pract, 2015.

[13] Graulich N. "The tip of the iceberg in organic chemistry classes: how do students deal with the invisible?," Chem. Educ. Res. Pr, 2015, 16 9-21.

[14] Anderson J., Purdue university (Purdue University),
2009.

[15] Galloway K. R. and Bretz S. L., "Using cluster analysis to characterize meaningful learning in a firstyear university chemistry laboratory course" Chem. Educ. Res. Pract, 2015, 16 879-92.

[16] Flynn A. B. and Biggs R., "The Development and Implementation of a Problem-Based Learning Format in a Fourth-Year Undergraduate Synthetic Organic and Medicinal Chemistry Laboratory Course", 2015, 52-7 Vol. 10. 